siglo XIX; es decir, una clase privilegiada con una posición económicamente dominante en el sistema de producción.

Tras llegar a la conclusión de que la clase capitalista no sólo no ha desaparecido, sino que ha mantenido un nivel económico superior con respecto al resto de la población - como demuestra la tabla de las veinte familias más ricas de la sociedad británica--; que han alcanzado su influencia en sectores económicos tales como: propiedad urbana y agrícola, alimentación, comercio e industria... El autor quiere demostrar, frente a las aportaciones del marxismo más ortodoxo, que el cambio en la estructura y en las formas de control, «Managers» de las grandes corporaciones, tanto a nivel nacional como internacional, no implican un desplazamiento de la clase capitalista.

Ahora bien, si la clase capitalista no ha desaparecido, la estructura de clases y mecanismos de reproducción si se ha alterado. El talento y el mérito no son suficientes para alcanzar el vértice de la pirámide social. La reproducçión de la estructura matrimonial con similares éxitos sociales, permite perpetuar la riqueza familiar y su propiedad. La aristocracia "upper class», junto con las clases altas de los distintos grupos religiosos: católicos, judíos ... y el predominio de los terratenientes y sus valores, enfatizan su superioridad a nivel político y social.

La clase capitalista, no sólo mantiene sus privilegios y ventajas de heredar un acceso a las localizaciones principales de la empresa, sino que la importancia de los «Public Schools» de Oxford y Cambridge, en la adquisición de credenciales de educación, la permiten diferenciarse en comportamientos, gustos y capacidad de oratoria. Este proceso, igualmente reconocido por Miliband, opera en la élite estatal. Aquellos que controlan la selección y promoción llevan en su mente «una imagen particular de como un alto funcionario o militar debe pensar, hablar, comportarse y reaccionar». Los «Public Schools» y Oxbridge, son los fundadores de estas redes que conectan varios círculos sociales entre sí. Los miembros de los principales clubs de Londres, refuerzan esas conexiones mediante una serie de mítines informales entre antiguos alumnos para promover nuevas oportunidades a nivel de carrera e intereses.

En la última parte de la obra, Scott trata de demostrar como la actual clase capitalista, entendiendo por ésta los intereses económicos, comerciales y financieros de la «City», ha modificado el bloque dominante, pasando a ocupar la principal posición. Esta transformación de los intereses económicos ha conducido a un cambio en la estructura capitalista de clases. En consecuencia, la élite del poder no está dominada por el «establishment» de finales del siglo $X I X, y$ principios del siglo $X X$, en cuanto a «status» se refiere, sino por un «inner circle» que refleja el punto de vista de la «City" en cuanto a la formulación de las políticas públicas.

Si bien la aportación de Scott es novedosa en el sentido de enriquecer el análisis del poder del estado y superar la simplificación del marxismo ortodoxo, mediante la introducción de nuevos conceptos como bloque de poder, élite de poder segmentada y fragmentaria, la utilización que en determinados momentos hace de los mismos puede generar una cierta redundancia y confusión en el lector. De cualquier manera la explicación de la formación del poder mediante la revisión e incorporación de las distintas aportaciones teóricas - marxistas, pluralistas y estructuralistas - permiten un enriquecimiento considerable capaz de evitarel reducionismo en tema tan importante y complejo.

Rocío Valdivielso del Real

\section{A Simple Matter of Salt. An Ethnography of Nutritional Deficiency in Spain}

\section{Renate Lellep Fernández \\ Berkeley, Univ. of California Press, 1990}

\%\%\%\%

La tesis doctoral que $R$. Lellep ha presentado en la Universidad de Rutgers, en Estados Unidos, tiene un título expresivo de las motivaciones y actitudes de la autora al emprender su investigación en 1965.

En un valle asturiano que con su marido, J. Femández, viene estudiando desde hace veinticinco años, la frecuencia de irastomos tiroideos se asocia al fatalismo en los afectados y en los profesionales sanitarios. A pesar de los buenos resultados que para prevenir el bocio endémico, ha tenido en otros países la administración masiva de sal iodada, la Sanidad española se ha resistido o desentendido del tema. En los años veinte, cuando iniciaron esta medida profiláctica Suiza y los Estados Unidos de América, Marañón la deșestimó por otra tan compleja e imprevisible como el desarrollo económico global de las zonas endémicas. Las propuestas de E. Carrasco en 1934 no fueron oídas. Sólo recientemente Ortíz de Landázuri. Monrreale de Castro e Ibáñez González confirman la eficacia de tomar el problema como «una simple cuestión de sal» (el título del libro), y Escolar del Rey desestima, tras estudio en Las Hurdes, la atribución de la enfermedad a la consanguinidad. En Asturias, la llegada de 
los socialistas al poder político conlleva la asunción de que el bocio endémico se ha de tratar con medidas de complemento dietético en la población general.

El cambio de actitud en las autoridades sanitarias y en algunos profesionales se ha producido al tiempo que la autora llevaba a cabo su investigación y es probable que haya influido en ello esa antropóloga americana que entrevistaba a endocrinólogos de Asturias y Madrid para preguntarles es decir, instarles-, por qué en España no se tomaban medidas tan simple como esa. Si así fuese, se habría logrado el objetivo de un estudio que tiene algo de investigaciónacción.

Las respuestas que encontró fueron variadas. Desde quien participaba de su escándalo ante el fatalismo y la inercia a quienes argüían que las cosas no son tan simples, ni la etiología está clara ni la distribución de sal el mejor modo de prevenir el bocio.

El afectode la antropóloga hacia las mujeres de Escobines, una aldea asturiana en la que pasa temporadas, le llevó a plantearse una investigación de Antropología aplicada, que caracteriza con el subtítulo «Una Etnografía de la deficiencia nutritiva en España».

Es a partir de ahí, a mi entender, donde las buenas intenciones y el evidente esfuerzo se orientan erróneamente para el objetivo que se propone, aunque dan lugar a una descripción etnográfica muy rica y completa y uno de los primeros diagnósticos de salud de una comunidad en España. De las limitaciones en aquel aspecto nos compensan con creces la novedad y riqueza de éste.

Pero para conocer las barreras culturales a la prevención en la población rural (ignorancia, fatalismo, consideración solamente estética del bocio) y los intereses corporativos de los sanitarios parece que lo adecuado sea un estudio institucional con enfoque emic. Efectivamente, lo emprende, aunque limitado para los objetivos que se pretenden e inmerso en una revisión global de todos los aspectos sanitarios del bocio (genéticos y ambientales), para intentar demostrar a los médicos y políticos asturianos que la etiología del bocio es ambiental y no genética. Como si la base genética fuese excluyente de tomar medidas dietéticas y si en estos pagos el esclarecimiento científico moviese automáticamente a actuar en consecuencia.

Y así, frente al encandilamiento de aquellos médicos por la Medicina hospitalaria de alta tecnología, reivindica la eficacia de la Salud Pública de baja tecnología.

Como ella es antropóloga y no epidemióloga, se basa en un enfoque cualitativo, genealógico y comunitario, dejando de lado el que pudiesen ser complementario estudio estadístico, de enfoque cuantitativo y distributivo. La limitación metodológica no sería tal si las intenciones fuesen simplemente descriptivas, pero R. Lellep atribuye a los resultados un valor explicativo.

En aquel momento no se estaba haciendo nada al respecto en Asturias, por lo que parecía lícito que para sensibilizar y elaborar hipótesis se pudiera obviar refinamientos en la recogida y tratamiento de los datos. Pero eso ya no es válido cuando se trata de sacar conclusiones del alcance que pretende la autora.
En el estudio genético de las mujeres de Escobines se aprecian algunas insuficiencias, que pueden restarle valor a los ojos de los sanitarios, de por sí más acostumbrados al cientifismo epidemiológico que a las visiones antropológicas.

Al elaborar árboles genealógicos de una población amplia -800 mujeres de tres generaciones de las que 258 desarrollaron un bocio- utiliza el «método visual» para el diagnóstico, y la visión global de las genealogías para deducir relaciones de transmisión genética. No tiene en cuenta que el bocio es la expresión de distintas enfermedades (metabólicas, lesión por infección, autoinmunidad o estimulación emocional); que los primeros estadios se diagnostican por otros síntomas que el bulto en el cuello y por pruebas bioquimicas; que la transposición del genotipo al fenotipo no es automática, sino que hay distinta penetrancia, variabilidad en el período de latencia y expresibidad diferente una vez desencadenado, además de que hay enfermedades genéticas que no han sido heredadas porque son mutaciones y que las multifactoriales resultan de la predisposición genética y el elemento ambiental desencadenante; que la transmisión genética no suele seguir los esquemas mendelianos simples, sino que en muchos casos es poligénica y sólo atribuible por la proximidad de cada caso a tablas de lasas empíricas; que para encontrar la proporción de homocigóticos, en los que se pueden hacer aparentes los genes recesivos, la consanguinjdad sólo tiene valor en el análisis de un árbol genealógico si se enmarca en la consanguinidad general en esa población y nos atenemos a la fórmula de Weinberg-Dahlberg. Sin contar con las inmensas posibilidades diagnósticas - muy pronto terapeúticas - de la «nueva genética»-, con estudios moleculares del ADN de los genes y del ligado de ellos.

Esa limitación explicativa no supone menoscabo, otros valores hacen su lectura interesante.

El enfoque holístico de la enfermedad y la prevención se plasma en la superposición de estudios parcelares sobre la misma población y su ambiente: geológicos (tierras calizas competitivas con el iodo), climáticas (lluvias que conllevan aguas pobres en iodo), dietéticas (escasez de carnes y otros aportes iodados e importancia de antagonistas como berzas, rábanos y castañas), económicos, sociales, políticos, asistenciales $\mathrm{y}$ de creencias en relación con esa enfermedad. Enfoques etic y emic sobre un mismo ámbito y distintos aspectos de un problema. Ejemplificación de que en la salud pública se han de tener en cuenta todos los componentes, incluso cuando experiencias anteriores acreditan que el problema se resuelve con medidas simples, como el suplemento dietético con sal iodada.

Por cierto, ¿cómo es que se han olvidado los factores emocionales en el desencadenamiento del bocio si hoy en día se sabe de la psicosomática de la autoinmunidad y hay noticias desde antiguo de un cuadro tan sugerente para el antropólogo como el «hipertiroidismo de la noche de bodas»?

Esa consideración global hace que algunos aspectos iluminen otros, lo que no suele darse en los estudios epidemiológicos, aunque sean multivariados.

Por otro lado, en los países con la Sanidad desarrollada 
al nivel de España, sigue habiendo sectores de la población oscuros para los organismos de vigilancia epidemiológica, por su escasa relación o su dispersión en diferentes centros asistenciales. Además de los enclaves rurales, en las ciudades hay grupos marginados como los gitanos, los extranjeros y las prostitutas que son poco conocidos sanitariamente, a pesar de que su estado de salud tiene una trascendencia social más amplia que la del grupo.
Los estudios antropológicos y globales, como el de $\mathrm{R}$. Lellep siguen siendo extremadamente interesantes para desvelar problemas y sugerir hipótesis. A pesar de la destreza de la autora para analizar y combinar documentos, observaciones y testimonios, la verificación probablemente ganaría si se llevase a cabo por equipos multidisciplinarios.

Felipe Reyero

\section{Sociedad y lenguaje. Una lectura sociológica de Saussure y Chomsky}

$\% \% \% \% \% \% \% \% \% \% \% \% \% \% \% \% \% \% \%$

\section{Miguel Beltrán. \\ Madrid, Fundación Banco Exterior, 1991}

\%ळ\%ळ\%क

Los sociólogos suelen pasar del lenguaje. En revancha, algunos de ellos casi reducen la sociedad a lenguaje. Miguel Beltrán no es ni de los unos ni de los otros: pues acostumbra a moverse en un entorno próximo al fiel de la balanza. Reconociendo la mediación lingüística en la construcción social de la realidad, no llega a dar el giro lingüístico -cambio de objeto- pero llega a dar un semigiro - ampliación del objeto-. Lenguaje y sociedad no están para él ni en relación de exclusión ni de inclusión: sino de intersección.

Beltrán está abierto a la toma en cuenta del lenguaje como objeto de reflexión para el sociólogo, en los planos tanto teórico como metodológico. Como ejemplo, en $L a$ realidad social (Tecnos, 1991) lo demuestra. El capítulo 5 («El lenguaje como realidad social», publicado antes como artículo, y reelaborado como introducción a Sociedad y lenguaje) refleja su valoración del lenguaje en el plano teórico ( «Es claro que el mundo social está linguíísticamente mediado, y no falta quien dice que en buena medida es lenguaje; de aquí la necesidad de subrayar que el animal humano, en tanto que zoón politikón. es por ello mismo animal ladino, o locuaz; por lo que el lenguaje y su uso deben encontrar en la teoría sociológica la atención que sin duda requieren», pp. 137-138). El capítulo 4 («Cinco vías de acceso a la realidad social», publicado como artículo, e incluido antes en otro libro) su valoración en el plano metodológico ( «la negación al lenguaje de su condición de dado, su cuestionamiento, implica una ruptura epistemológica que constituye el método cualitativo» (...) «no puede ocultarse al investigador que no hay datos inmediatos, sino que todos estân lingüísticamente producidos, esto es, mediados»). Como objeto y como instrumento, el sociólogo debe contar con el lenguaje, de otro modo, el lenguaje contaría con él.

Ahora, Beltrán ha asumido la asombrosa disciplina de una lectura atentísima y casi exhaustiva de la obra de los cabeza de fila de las dos escuelas linguiísticas más seguidas del mundo occidental: Saussure, desde el estructuralismo, y Chomsky, desde el generativismo. Decía Deleuze que es posible unificar una dispersión desde dos dimensiones, buscando, bien un eje genético, bien una estructura profunda. La historia es un proceso de rupturas de simetrias, de surgimientos de textos heterogéneos en contextos homogéneos. Los unificadores buscan las simetrías perdidas en el pasado, los diversificadores encuentran las asimetrías producidas en el futuro. Chomsky y Saussure son unificadores. Beltrán, como la mayoría de los sociólogos, diversificador. Como diversificador, filtra la lingüística para recuperar las trazas que ta historia - la contingencia - ha dejado en el lenguaje.

El meollo de su argumento es una crítica a ambos autores por no haber tenido en cuental suficientemente la naturaleza social del lenguaje. Como los sociólogos no tienen en cuenta la naturaleza lingüística de la sociedad. Entre sociología y lingüística hay un abismo que apenas colman dos cuñas intersticiales: la sociolingüistica, y la sociología del lenguaje. Beltrán contribuye a colmar ese abismo.

Saussure divide - analíticamente - el lenguaje en «lengua» (componente social) y «habla» (componente individual): de ambos componentes niega explícita o implícitamente su carácter social. Explícitamente, del «habla»: para él es un fenómeno individual. Lo que a Beitrán le parece aberrante: «Es tan social como la lengua. Toda interacción es acción social» (p. 37). Implícitamente, de la lengua: Saussure, coherente con su concepción de la arbitrariedad del signo, aísla la lengua de su contexto social (de ahí, la primacía de la sincronía sobre la diacronía). Para Saussure, el cambio no ocurre en el sistema de la lengua, sino en sus elementos (que, indirectamente, contribuyen al cambio del sistema). Como metodólogo, crea su propio objeto. Las operaciones analíti- 